\title{
Self-Determination and Individuals With Significant Disabilities: Examining Meanings and Misinterpretations
}

\author{
Michael L. Wehmeyer \\ The Arc National Headquarters
}

There appears to be a belief held by many people, both in the field of disability services and among people in the general public, that self-determination is a topic not relevant for people with significant disabilities. This article reviews how the term has been defined and conceptualized, examines misperceptions of the term that may have contributed to the exclusion of people with significant disabilities, and seeks to find common ground to move forward to promote self-determination for people with significant disabilities.

DESCRIPTORS: adults, choice making, decision making, quality of life, Rehabilitation Act

This special issue of $J A S H$ provides an opportunity to address a question that is important both for and to people with significant disabilities and for conceptualizing and understanding self-determination: "How does self-determination apply to people with significant disabilities?" The importance of this question depends as much on what remains unasked but is often implied; that is, the underlying meaning of this question too often is "Does self-determination apply to people with the most significant disabilities?" Many people, including people working in the disability services field, apparently believe that people with significant disabilities cannot be self-determined, a state of affairs noted by several researchers and writers in this area (Brown \& Gothelf, 1996; Stancliffe \& Abery, 1997; Wehmeyer, 1996a).

Why does the assumption that people with significant disabilities cannot or do not become self-determined exist? There are several reasons for this, each of which will be discussed subsequently, but I believe that the overarching reason for this circumstance relates to how selfdetermination is defined, conceptualized, and operationalized. The answer to the question "What is self determination?" circumscribes the answer to the question, "How does self-determination apply to people

Address correspondence and requests for reprints to Michael L. Wehmeyer, Assistant Director, Department of Research and Program Services, The Arc National Headquarters, 500 East Border Street, Suite 300, Arlington, TX 76010. with significant disabilities?" Until we can answer the former, the latter will remain uncertain and prone to misinterpretation.

The premise of this article is that because the meaning of the term has not been understood clearly or, more specifically, has been misunderstood, there is a growing and fundamentally mistaken belief that it does not or cannot apply to people with significant disabilities. The following section examines issues related to the definition of self-determination and explores current conceptualizations. The second section examines misconceptions of the construct and their influence on how self-determination is conceived for people with significant disabilities.

\section{Defining Self-Determination}

The term self-determination has two primary meanings, both of which have a long history of use outside the disability field. The American Heritage Dictionary of the English Language (1992) identifies self-determination as a noun and defines it as:

1. Determination of one's own fate or course of action without compulsion.

2. Freedom of the people of a given area to determine their own political status; independence.

Self-determined and self-determining are listed as adjectival forms of the noun self-determination. That is, a self-determined person is someone who determines his or her own fate or course of action without compulsion, whereas a self-determined country is one in which the people have the freedom to determine their own political status. Both meanings are roughly synonymous with the term self-governing, an adjective that means (1) exercising control or rule over oneself or itself or (2) having the right or power of self-government (The American Heritage Dictionary of the English Language, 1992). The difference between the two meanings is the referent for the noun self, which can be defined either as referring to a person (e.g., oneself) or an entity (e.g., itself). The first meaning of the construct is one of $a$ personal self-determination; controlling one's life and one's fate. The second meaning refers to a national, 
political, or collective self-determination; the right of a nation or a group of people to self-governance.

\section{National, Political, or Collective Self-Determination}

The national or political sense of the term was used first during Woodrow Wilson's second presidential term. In 1918, as World War I drew to a close, President Wilson formulated 14 points that would offer selfdetermination (as self-government) to the European national groups involved in the war and pave the way for general disarmament. This usage remains the most common application of the term, primarily within the field of political science. Although most frequently used to refer to the right of a nation or country to selfgovernance, the term has equal applicability to people whose group identity is defined by criteria other than geographic boundaries, including people selfidentified by cultural or racial characteristics (e.g., Native American self-determination), sexual orientation, gender, or disability status. For example, Vaughan (1993) refers to the "struggle of blind people for self-determination."

\section{Personal Self-Determination}

The second use of the term, that of a personal selfdetermination, emerged in the early 1940s along with the development of the field of personality psychology, although related debates around "determinism" (dis cussed subsequently) have been around for centuries. There is often confusion associated with the term determination as it pertains to the construct selfdetermination. The noun determination has multiple meanings, including: (1) the act of making or arriving at a decision or the decision reached (e.g., the choice of a foster home was left to the court to determine) and (2) firmness of purpose or resolve (e.g., he was determined to succeed) (The American Heritage Dictionary of the English Language, 1992).

The personal form of self-determination (e.g., determination of one's own fate or course of action without compulsion) is not just adding the "self-" referent to the first meaning of determination, thus referring only to a decision one made. Nor is it synonymous with the second definition (firmness of purpose or resolve), despite the tendency of many people to use self-determination in this manner. In fact, the meaning of determination in self-determination is synonymous with determinant, defined as "an event or antecedent condition that in some way causes an event" (Wolman, 1973). Determinants of human behavior (e.g., causes of human behavior) include physiological, structural, environmental, and/or organismic factors. Similarly, determinism is the doctrine that all phenomena, including behavior, are effects of preceding causes (Wolman, 1973).

This intent is clearly seen in the earliest uses of the term as a personal construct. In his 1941 text Foundations for a Science of Personality, Angyal proposed that an essential feature of a living organism is its autonomy, where autonomous means self-governing or governed from inside. According to Angyal, an organism "lives in a world in which things happen according to laws which are heteronomous from the point of view of the organism." Heteronomous means governed from outside; according to Angyal "organisms are subjected to the laws of the physical world, as is any other object of nature, with the exception that it can oppose self-determination to external determination." Angyal argued that the science of personality is in essence the study of two essential determinants of behavior, autonomous determination (or self-determination), and heteronomous determination (other determined).

\section{Self-Determination and Disability}

Among the first, if not the first, use of the term within the disability literature occurred in a chapter by Nirje (1972) in Wolfensberger's (1972) now classic text on the principle of normalization. Nirje (1972) titled his chapter The Right to Self-Determination and in the opening paragraph stated:

One major facet of the normalization principle is to create conditions through which a handicapped person experiences the normal respect to which any human being is entitled. Thus the choices, wishes, desires, and aspirations of a handicapped person have to be taken into consideration as much as possible in actions affecting him. To assert oneself with one's family, friends, neighbors, coworkers, other people, or vis-à-vis an agency is difficult for many persons. It is especially difficult for someone who has a disability or is otherwise perceived as devalued. But in the end, even the impaired person has to manage as a distinct individual, and thus has his identity defined to himself and to others through the circumstances and conditions of his existence. Thus, the road to self-determination is both difficult and all important for a person who is impaired.

Nirje's (1972) use of the term suggests, at the least, familiarity with the usage of self-determination as a personality construct. His use of the term, although still pertaining to the rights of a particular group of people (e.g., people with mental retardation), is nonetheless a call for personal self-determination or self-governance. Nirje (1972) identified making choices, asserting oneself, self-management, self-knowledge, decision making, self-advocacy, self-efficacy, self-regulation, autonomy, and independence (albeit often not using those terms) as the salient features of this personal selfdetermination. His is a call for a wide range of action, that enable people to control their lives and their destinies, including choice over personal activities, control. 
over education, independence, participation in decisions, information on which to make decisions and solve problems, and so forth.

Nirje clearly articulated the importance of this personal self-determination for all people, not excluding people with mental retardation or other significant disabilities. Throughout the chapter Nirje equates selfdetermination with the respect and dignity to which all people are entitled. More so, Nirje recognized that people define themselves and others define them by the circumstances and conditions of their existence. This recognition that self-determination is fundamental to attaining respect and dignity and to perceiving oneself as worthy and valued is a major reason people with disabilities have been unequivocal and consistent in their demand for control in their lives.

An analysis of Nirje's chapter to determine the types of actions, beliefs, and opportunities that describe self-determination reflects the same breadth and scope seen in the literature today. Nirje (1972) identified making choices, asserting oneself, self-management, selfknowledge, decision-making, self-advocacy, selfefficacy, self-regulation, autonomy, and independence (again, often not using those terms) as the salient features of personal self-determination. Nirje included a list of platform statements made by people with mental retardation involved in a self-help group; this list illustrates the scope of self-determination:

- We want to choose our vacations ourselves and have influence over our education.

- We demand that our capacity for work should not be underestimated.

- We demand more information about our handicap and our job prospects.

- We want to have leisure time together with other (young) adults of the same age.

- We want to have an apartment of our own and not be infantilized.

- We think that we should be present when our situation is discussed by doctors, teachers, welfare workers, and foremen (Nirje, 1972).

Even within this limited list, one not intended to define self-determination in any way, there is a call for a wide range of actions that enable people to control their lives and their destinies, including choice over personal activities, control over education, independence, participation in decisions, information on which to make decisions and solve problems, and so forth.

The fourth point to emphasize from Nirje's call for self-determination is that it was made in reference to people who experienced a significant disability; people who were, at that time, placed in institutions, denied educational opportunities, and, ultimately, denied the right to self-determination. Nirje's chapter appeared in the same book in which Perske (1972) called for the opportunity for people with mental retardation to experience the "dignity of risk":
The world in which we live is not always safe, secure and predictable ... Every day that we wake up and live in the hours of that day, there is a possibility of being thrown up against a situation where we may have to risk everything, even our lives. This is the way the real world is. We must work to develop every human resource within us in order to prepare for these days. To deny any person their fair share of risk experiences is to further cripple them for healthy living.

These two important calls to action emphasized the universality of the desire for control in one's life and, one's destiny and over decisions and choices that impact one's life and one's quality of life. These historic calls and the expanding literature base that has emerged in the last decade in this area emphasize the importance of self-determination in the lives of people with and without disabilities.

\section{What Do People With Disabilities Mean When They Demand Self-Determination?}

There have been two major initiatives that have focused attention on self-determination in the disability services community and influenced how people in the field understand the term self-determination. The earliest was the U. S. Department of Education, Office of Special Education's self-determination initiative, which funded from 1990 to 199626 model demonstration and five assessment development projects to promote selfdetermination for youths with disabilities (Ward, 1996; Ward \& Kohler, 1996). These projects, and other education-related efforts, have resulted in numerous frameworks within which the term self-determination, has been defined (Abery, 1993; Brown \& Gothelf, 1996; Field, 1996; Field \& Hoffman, 1994; Mithaug, 1996; (Powers et al., 1996; Sands \& Wehmeyer, 1996; Wehmeyer, 1996b; Wehmeyer, Agran, \& Hughes, 1998; Wehmeyer, Kelchner, \& Richards, 1996), and in a larger number of efforts to promote self-determination that implicitly define self-determination by the types of activities and interventions introduced and implemented (Agran, 1997; Carter-Ludi \& Martin, 1995 Martin \& Marshall, 1996; Serna \& Lau-Smith, 1995 Van Reusen, Bos, Schumaker, \& Deshler, 1994). Although some projects addressed school reform, they almost exclusively conceptualized self-determination as a personal construct.

The second major initiative has been the Robert Wood Johnson funded self-determination projects (Nerney \& Shumway, 1996; O'Brien, 1997). The intent of this initiative was to provide state agencies that have authority over developmental disability systems to implement changes in state policy and enact system change reforms based on the principles of selfdetermination. Projects funded under this initiative must engage in activities such as implementing indivi- 
dual budgets to be spent based on decisions made by people with disabilities and their families or helping service-providing agencies retrain employees to enable self-directed service brokerage. These ongoing projects address political or collective self-determination, focusing attention on systemic and overarching changes and reforms to support and enable individual control and choice.

These efforts reflect parallel activities leading toward what people with disabilities mean when they demand self-determination. That is, people with disabilities want both political and personal self-determination. They want to have the freedom to direct and control their own lives and to be enabled to take advantage of such opportunities. Most simply put, self-determination means people or peoples controlling their lives and their destinies. It is both that simple and that complex.

\section{Conceptualizing Self-Determination}

Simply knowing that self-determination means people or peoples having control over their lives and destinies does not provide adequate information to be used to enable people to become self-determined. This is true for either a personal or political self-determination. If self-determination is a legally protected right, then efforts to promote self-determination will focus on ensuring legal protection and compliance with the law. On the other hand, if it is a value or principle, there will be no law to enforce and efforts to promote selfdetermination will focus on educating people, changing attitudes and values, and changing systems to be responsive to such principles. Likewise, if self-determination is an innate capacity, it may be much more difficult to promote than if it is something that is learned. Thus, conceptualizations of self-determination provide that focus and drive efforts to promote self-determination.

A review of the literature identifies several such conceptualizations, including self-determination as a right, an ideal or principle, an innate drive or internal motivation, a capacity, a process or outcome, or as a trait or characteristic of a person. Conceptualizations or theories of any construct are intended to organize and integrate all that is known or assumed about that construct in an effort to predict and define behavior and/or drive research, policy development, and practice. Hall and Lindzey (1957) noted that theories are neither true nor false, only useful or not useful. Such is the case for conceptualizing self-determination, either at a political or personal level. Such conceptualizations should be judged by a number of factors, including their heuristic value, the degree to which they incorporate known facts and knowledge (e.g., reflect the definition of selfdetermination as control), their explicitness and testability, and their simplicity. All conceptualizations and/ or theories contain assumptions, usually based on specific beliefs about or understandings of how people learn, think, or develop and why people behave as they do. Conceptualizations of self-determination are no different, given that they are basically conceptualizations and theories about how and why people or peoples assume control over their lives and their destinies. Not surprisingly, such conceptualizations have emerged from various disciplines and theoretical orientations. However, they can ultimately be linked to one or the other meaning of the term political or personal selfdetermination).

Two common ways of conceptualizing selfdetermination have limited usefulness, not because of any affiliation with a particular theoretical orientation or flaw in reasoning, but because they are not really conceptualizations of the term, per se. The first is that self-determination is either a process or an outcome. It is true that there is a process (actually any number of theoretical processes) that combines aspects of devel opment, learning, opportunity, and experience that lead to a person becoming self-determined (Doll, Sands, Wehmeyer, \& Palmer, 1996) or a process leading to a group of people gaining political selfdetermination. However, political or personal control over one's life is not in and of itself a process. Gaining control over one's life is a process, being in control of one's life is not but is instead a state, status, or outcome. There is, as such, some usefulness to talking about selfdetermination as a desired outcome, both at a personal level or at a political level, where outcome refers to the consequence of an action, activity, event, or behavior. Thus, educators can focus on promoting selfdetermination as an outcome of the educational process or policy makers can emphasize self-determination as the outcome of a political or legislative process. However, discussing self-determination as an outcome or a process does not move any closer to understanding the construct itself. Take the construct "literacy" as an example of this issue. Literacy is a valued outcome for education, or, more accurately, achieving literacy is a valued educational outcome. However, calling literacy an outcome does not tell us what it is. Literacy is, of course, the capacity to read and write. Similarly, discussing self-determination as an outcome has value for emphasizing the importance of this construct and for describing what an effort is trying to achieve (Field, Martin, Miller, Ward, \& Wehmeyer, 1997; Wehmeyer, 1996b) but not for conceptualizing and better understanding the construct.

A second conceptualization, self-determination strictly as capacity, is addressed in detail later and subsequently will not be dealt with here. Essentially, however, self-determination can neither be adequately defined nor conceptualized as a set of specific skills or behaviors, and conceptualizations equating selfdetermination strictly with capacity are both inaccurate and, in the end, discriminatory. The remaining conceptualizations (self-determination as a right, ideal, or 
principle, as an innate drive or internal motivation, of as a trait or characteristic of a person) are among those currently proposed that meet Hall and Lindzey's (1957) criterion of usefulness. As previously mentioned, these reflect the two meanings of self-determination defined earlier, with national or political self-determination conceptualized as a right, ideal, or principle and personal self-determination defined as a drive, motivation, trait, or characteristic.

Conceptualizing political, national, or collective selfdetermination. Political or national self-determination has been conceptualized largely as a principle, ideal, or right, with most people with disabilities emphasizing the latter. Technically speaking, a right is "a valid, le gally recognized claim or entitlement, encompassing both freedom from government interference or dis criminatory treatment and an entitlement to a benefit or service" (Levy \& Rubenstein, 1996). In our society citizens have the right to the opportunity to live selfdetermined lives. They have the right to free speech and association, the right to be free from discrimination, the right to due process, and so forth. References to the right of self-determination are essentially applicable only to the use of the term to groups and as meaning self-governance. There are, however, a number of rights that have been upheld that are important to selfdetermination. Levy and Rubenstein (1996) identified the rights to personal liberty incorporated in our legal system as including the rights to bodily integrity and privacy, the right to provide informed consent, and the right to refuse treatment. It is beyond the scope of this article to provide a detailed treatment of topics related to the rights of people with significant disabilities that impact self-determination. However, when individuals refer to the "right of" (as opposed to the "right to") selfdetermination, they really refer to the rights of people to be free from discrimination, to be free from invol untary commitment, to have privacy, to free speech and free association, and the myriad of protections that in essence provide a person the opportunity to become selfdetermined.

However, there is another use of the term right that does not refer to a legally protected claim, but instead to basic rights and freedoms to which all human beings are entitled, often held to include the right to life and liberty, freedom of thought and expression, and equality before the law (The American Heritage Dictionary, 1992). This sense, synonymous with terms like ideal and principle, includes the right to control one's life and destiny. For example, Jakubowski and Lange (1978) surveyed U. S. citizens to determine what they perceived as basic human rights and found that items like "the right to be treated with respect," "the right to ask for what you want," and "the right to act in ways that promote one's dignity and self-respect" have wide acceptance among the public. These are not codified in law as much as contained in the values held by citizens in a given society and are generally accepted, though not civilly protected. In this sense of the word, selfdetermination is a basic human right, or more accurately a principle or ideal. That was in essence Nirje's (1972) argument and is the meaning inherent in most calls by people with disabilities and other advocates for access to personal control and self-determination. Mithaug (1996) provides a comprehensive examination of this right to selfdetermination and the expression of that right, particularly as it pertains to people who have historically been disenfranchised, including people with disabilities.

Conceptualizing personal self-determination. There have been numerous conceptualizations of self-determination proposed within education and psychology and additional conceptualizations that address personal control and causation that do not use the term self-determination. It is not the purpose of this article to provide an exhaustive or critical examination of these conceptualizations, but instead existing conceptualiza tions are briefly discussed as examples of the conceptualizations of personal selfdetermination that have been proposed to date.

Motivation researchers, primarily Deci and Ryan (1985), conceptualized self-determination as an internal need contributing to an individual's performance of intrinsically motivated behaviors. Self-determination is, in their conceptualization, "the innate, natural propensity to engage in one's interests and exercise one's capacities, and in so doing, to seek and conquer optimal challenges" (Deci \& Ryan, 1985). Similarly, Abery (1994) conceptualized self-determination as "an intrin sic drive to be the primary determiner of one's thoughts, feelings, and behaviors."

Powers et al. (1996) conceptualized self-determination as a function of mastery motivation (characterized by perceived competence, self-esteem, maintenance of an internal locus of control, and internalization of goals and rewards) and self-efficacy expectations. Mithaug (1996) offers a conceptualization of self-determination as a variant of self-regulation in which individuals engage in selfregulated problem solving to satisfy their own needs and interests.

Wehmeyer (1996b, 1997) and Wehmeyer et al. (1996) proposed that self-determination refers to a dispositional characteristic of individuals. Dispositional characteristics involve the organization of cognitive, psychological, and physiological elements in such a manner that an individual's behavior in different situations will be similar (though not identical). According to this conceptualization, people can be described as self-determined based on the functional characteristics of the behavior. Wehmeyer (1996b, 1997) and Wehmeyer et al. (1996) proposed four essential characteristics of self-determined behavior: (1) the person acted autonomously, (2) the behavior(s) were self-regulated, (3) the person initiated and responded to the event(s) in a psychologically empowered manner, 
and (4) the person acted in a self-realizing manner.

The debate regarding what or who determines or causes the behavior of organisms is at the core of the discipline of psychology and, as Angyal (1941) suggested, is the fundamental question when seeking to explain, predict, and change human behavior. As such, the relative contribution and impact of various determinants of behavior remains a point of disagreement among and between theorists of differing orientations. It is beyond the scope or intent of this article to delve into the multiple theoretical orienttations that attempt to explain human behavior as it relates to self-governance and control other than to note that theories and conceptualizations of personal selfdetermination will vary according to the theoretical orienttation of the individual theorist. In fact, some theorists eschew the use of the term self-determination because of its historical alliance with philosophical conceptualizations of free will or its more modern association with theories of internal motivation. However, in its present use, particularly within the disability field, self-determination has less to do with the historic understandings of deteminism or free will and more to do with understanding and explaining the internal and external, indeed the autonomous or heteronomous, determinants of behavior and harnessing this understanding to effect change.

\section{Misinterpretations of Self-Determination}

If the earliest call for self-determination for people with disabilities was on behalf of people with the most significant disability (Nirje, 1972), why is it that we stand at the crossroads now having to respond to an apparently widely held assumption that people with significant disabilities do not or cannot become self-determined? More importantly, if control over one's life and one's destiny is universally desired and if living a selfdetermined life defines who one is and who others perceive one to be, why is it that people with significant disabilities should not both desire this and have access to opportunities to achieve this end? The answer to the latter question is that people with significant dis abilities do in fact desire self-determination and should be provided the experiences and opportunities that lead to this outcome. The answer to the former question (e.g., "Why is there a belief that people with significant disabilities cannot or will not be self-determined?") is at least partly a function of how we define self-determination or more realistically how it has been interpreted or understood. Interpretations of self-determination that either exclude indivi duals by categorical membership, like people with significant disabilities, or limit the scope and breadth of selfdetermination as reflecting control over one's life and destiny are, intentionally or unintentionally, discriminatory.
Over the past few years there have emerged a number of misinterpretations of self-determination that have contributed to the belief that people with significant disabilities will not, or perhaps cannot, become selfdetermined. This section examines several of these misinterpretations, some of which apply to understandings of personal self-determination, others that apply to collective self-determination, and some that apply to both meanings.

\section{Misinterpretation 1: Self-Determination as Independent Performance}

When self-determination is interpreted strictly to mean "doing it yourself," there is an obvious problem for people with significant disabilities, many of whom may have limits to the number and types of activities they can perform independently. However, the capacity to perform specific functions is secondary in importance in achieving self-determination to whether one has control over the outcomes such functions are implemented to achieve. Control is defined as "exercising authoritative or dominating influence over" (American Heritage Dictionary, 1992) and is synonymous with the verb "direct," meaning to manage. [For definitional purposes, however, the term control is preferable to either direct or manage (e.g., selfdetermination is directing one's life) because control is also synonymous with power and retains the emphasis on empowerment inherent in the use of the term within the disability community.]

Self-determination is not just the independent performance of behaviors. People who have significant physical disabilities can employ a personal assistant to perform routine activities and if such functions are performed under the control of that person (e.g., person with disability) it is really a moot point whether the person physically performed the activity. Likewise, a person with a significant cognitive impairment may not be able to independently (e.g., alone and with no support) make a complex decision or solve a difficult problem. However, to the extent that supports are provided to enable that person to retain control over the decision-making process and to participate to the greatest extent in the decision-making or problem-solving process, he or she can be selfdetermined. In fact, there is almost always some aspect of even the most complex activities or tasks, from decisionmaking to goal setting, in which people with significant cognitive disabilities can participate with adequate support and accommo dations.

Rousso (1997) provides an excellent example of how exerting control in one's life and independent perfomance are often decoupled. She writes:

I know a sculptor who is quadriplegic. She sculpts by giving precise instructions to her assistants, who serve as her hands. While it is tempting to think that her assistants 
are the true artists, she is, in fact, the sculptor in charge. When she has given the same directions to two assistants who have had no contact with each other, they both produce identical pieces of sculpture. Through the experience of disability, this woman has learned to articulate her vision and her needs in direct, specific ways; so much so, that she gets precisely the help she needs in forms that are replicable.

\section{Misinterpretation 2: Self-Determination Is Absolute Control}

One of the drawbacks to the use of the term control is that many people view it as an absolute. That is, when they are told that self-determination means control over one's life, they think in terms of control as absolute dominion and authority, instead of other synonyms like influence, direct, or manage. Many people when presented with the suggestion that someone with a significant disability should be enabled/allowed to direct some aspect of his or her own life or to make choices immediately assume it means absolute control and construct a worse case scenario as a reason for denying such a move (e.g., "What if Johnny, who has diabetes, chooses to eat a dozen donuts, resulting in a potentially fatal reaction?").

Self-determination should not be equated with absolute dominion, nor is promoting self-determination equivalent to allowing chaos. From birth onward, humans depend on others. This dependence does not end with adolescence, but its nature changes. The developmental psychology literature conceptualizes autonomy as synonymous with individuation, the process by which children and young people move from being primarily dependent on others to survive and function, to becoming more self-reliant, selfsufficient, and less dependent on others (Damon, 1983). This is a movement from dependence to interdependence, not a movement from dependence to absolute dominion.

To avoid the confusion associated with the use of the word control, with its multiple meanings, I have suggested that the term causal agency may have greater usefulness because it retains the emphasis on control and empowerment while avoiding confusion from the multiple interpretations of the term control (Wehmeyer, 1996b). An agent is someone who acts on behalf of a person or entity. A causal agent is someone who causes or makes things happen in his or her own life. Causal agency implies that the person is an actor in his or her own life, instead being acted upon.

\section{Misinterpretation 3: Self-Determined Behavior Is Always Successful Behavior}

There is a tendency to equate self-determined behavior with successful behaviors. Although selfdetermination and positive outcomes have been linked (Wehmeyer \& Schwartz, 1997; Wehmeyer \& Schwartz, 1998), and it is likely that people who are more self-determined will be successful in their endeavors, there is an inherent danger for people with the most significant disabilities when self-determined behavior is defined as synonymous with successful behavior, because many people with significant disabilities are not perceived to be able to achieve success, as defined in typical societal standards. However, even self-determined people are not always successful. People who are effective decision makers use a series of strategies that enable them to enunciate a specific problem, identify potential solutions to the problem, identify the consequences of each solution, and choose from among those options. However, not every decision a person makes turns out to be an optimal decision, nor is every choice the perfect selection or every goal the right goal. People who are causal agents in their lives, who make things happen, who are involved in decisions, set goals, address problems, and make choices also experience negative outcomes from those activities. Otherwise, there would be no dignity to risk or at least no need to risk.

A definitional emphasis on successful outcomes is inappropriate. The emphasis should instead be on the attempt to exert control, to be a causal agent, and not predominantly on the outcome of such actions. On the other hand, someone whose actions consistently result in unsuccessful outcomes (and this assumes that a person has the opportunity to influence those outcomes) in all aspects of his or her life is probably not very selfdetermined. One aspect of self-determination emphasized in several of the conceptualizations identified earlier, including Nirje's (1972), is that self-determined people are self-regulating. One critical component of selfregulated behavior is that of adjustment ... examining whether the strategy or course of action one has used is effective and if not adjusting that strategy or behavior or selecting another. Marching through life making one poor choice after another, one ineffective decision after another, and failing to set or achieve goals suggests that the person is not self-regulating and not revising his or her strategies to achieve more positive outcomes in his or her life.

\section{Misinterpretation 4: Self-Determination Is Self-Reliance and Self-Sufficiency}

The terms self-sufficient and self-reliant are not typically associated with people with the most significant disabilities, who may need numerous and complex support systems to function as independently as possible. Just as self-determined behavior should not be definitionally contingent on successful outcomes, it should not be definitionally tied to absolutist interpretations of selfreliance or self-sufficiency. Self-reliance is defined as "reliance on one's own capabilities, judgment, or resources" (The American Heritage Dictionary of the English Language, 1992) and self-sufficient is defined as to "provide for oneself." Relying on oneself and provid- 
ing for one's needs can take many forms, including relying on one's own judgment and resources (not just monetary) to identify someone else who might better provide a desired outcome. In our complex society we rely on others to do things for us, from car repair to surgical procedures, and self-determination cannot be seen as simply reflecting the proportion of activities one performs independently, as discussed previously.

\section{Misinterpretation 5: Self-Determination Is Just Skills or Just Opportunity}

If relative self-determination is a function of the number or complexity of specific skills and abilities in one's repertoire, one might very well conclude that someone with a significant disability cannot become selfdetermined. However, although the types and number of skills one can learn does impact the degree to which one has control in one's life, so too does opportunity, the array and intensity of supports available, and one's experiences.

Defining self-determination as a set of skills or specific behaviors has limited use because virtually any behavior can be a reflection of self-determination. An attempt to define self-determination as a delimited set of behaviors (e.g., selfdetermination is just goal setting, self-advocacy, and leadership skills) ignores the fact that almost any behavior can be an expression of self-determination. Given that the purpose of defining a construct is to come to as precise a meaning as possible, a definition consisting of an almost infinite number of skills is both not very feasible or useful. In addition, such a listing will eventually include both the occurence and non-occurrence of a behavior as self-determined behavior (Wehmeyer, 1996b). Most definitions do not try to list all possible behaviors, but instead essentially describe what self-determined people typically do (e.g., solve problems, make choices, and set and achieve goals). Although such an exercise has some usefulness for creating a picture or image of a self-determined person, the image created rarely includes people with the most significant disability.

It is not, however, any more satisfying or accurate to conceptualize self-determination as relating strictly to opportunity than it is to view it as skills or capacities. Opportunity is important. Napoleon Bonaparte was reported to have said that ability is of little account without opportunity. Likewise, opportunity is of little account without ability. If one cannot take advantage of opportunities, the outcome is the same as never having had such an opportunity. It is a false dichotomy to conceptualize selfdetermination as exclusively skills or opportunity, as it clearly depends on equal parts of skills and opportunity mixed liberally with experience and adequate supports.

\section{Misinterpretation 6: Self-Determination as Something You Do}

There is a tendency for service delivery systems to create programs to implement innovations, with the unfortunate results too often being that the original intent or purpose of the initiative is lost in the implementation of the program and people who might otherwise benefit are excluded. One has to look no further than efforts to promote inclusion to see this happen. Well-intentioned schools have implemented inclusion programs that end up excluding some students based on eligibility criteria, often set because of limited resources. Even when the programmatization process does not result in the exclusion of people with significant disabilities, the original impact is often lost in the roll out. Thus, person-centered planning programs become just another meeting controlled by professionals or communitybased instruction programs become glorified field trips.

There is an emerging tendency to talk about selfdetermination as if it were a program or something one does. In the educational arena, attempts to have students actively involved in, indeed sometimes chairing, their education or transition planning meeting have been referred to as the district's self-determination program. Likewise, personcentered planning and service brokering efforts have been referred to as "doing self-determination" in adult services. Such efforts, well in tended or otherwise, fail to recognize that self-determination is not about a way to do planning or provide services, but is about enabling people to take control over. their lives and destinies. Student involvement in educational planning and decision making is a powerful vehicle to practice or learn skills like goal setting, decision making, problem solving, negotiation, or assertiveness. Likewise, person-centered planning may be an effective way to enable a person to identify his or her dream and to set goals for the future. Nevertheless, conceptualizing self-determination as a program, service, or procedure changes the meaning of self-determination from something a person or group of people is or has (e.g., control over one's life or destiny) to something someone, and usually someone else, does to or for the person. The fact of the matter is that a student can become self-determined without ever attending, more or less chairing, his or her educational planning meeting.

The dangers of this are that self-determination comes to be understood as just another curriculum, program, or service option with the almost certain result that the curriculum, program, or service option is not appropriate for someone, often someone with significant disabilities. For example, a flyer from a state-level effort to implement a self-determination program focusing on consumer-directed services described self-determination as encouraging choices while at 
the same time demanding the lowering of costs per individual. Such a definition of self-determination is destined to result in some of the same outcomes that have resulted with inclusion programs; services being cut primarily to save money, with responsibility for supports shifted without adequate resources, in essence dumping. Curricula, programs, and services can and should be designed and implemented to enable people to become self-determined or designed and delivered to support self-determination. However, these services, curricula, or programs are not in and of themselves selfdetermination. Professionals cannot "do" self-determination, but can do things to support, promote, and enable self-determination.

\section{Misinterpretation 7: Self-Determination Is a Specific Outcome}

Related to the tendency to associate self-determination with successful behavior and to view it as something one does is the tendency to equate selfdetermination with a specific outcome. No matter how positive the outcome is, it is inaccurate to define selfdetermination by that outcome. It is true that many people with disabilities must overcome incredible barriers to achieve such outcomes as owning their own home, getting married, getting a job, and so forth and that achievement of one or more of these outcomes might reflect the fact that they are self-determined (personally or politically) people. But there is nothing any more self-determined about living in a home you own than there is about living in a rented apartment or a leased trailer home. Likewise, there is nothing inherently self-determined about being married, divorced, or single; living with your parents or on your own; working or volunteering; or having children or not having children. Just as you cannot define self-determination based on a set of behaviors, because virtually any behavior could be an action to take control over one's life, virtually any outcome is one that might in fact reflect selfdetermination.

\section{Misinterpretation 8: Self-Determination Is Just Choice}

There is a pervasive tendency to view selfdetermination as synonymous with making choices. However, defining self-determination only as making choices places undue and inaccurate emphasis on only one aspect of being self-determined. Choice making is an important component of self-determined behavior, but so are problem solving, decision making, selfawareness, and goal setting. There are numerous problems with elevating choice as the ultimate value, both in conceptualizing self-determination and structuring efforts to promote self-determination. A colleague recently commented that she was concerned that selfdetermination was not for everyone because a participant in a project in which she was involved (exploring health care options for people who are elderly) had become quite anxious about having to make choices about her health care provider, physician, and plan. Her anxiety stemmed, at least partly, from the fact that she had grown accustomed to and comfortable with health care coverage that was, in essence, chosen for her. This woman had become used to a health care system in which she did not have to make some decisions or choices.

The issue at hand is not simply choosing but taking control over one's life. Different people want different levels of control over various aspects of their lives and have differing values about what they control. Some people want to personally select each stock in which they invest and to decide when to sell and when to hold Others prefer to invest their money in mutual funds where someone else, a skilled professional, buys, sells and manages the money. The elderly woman who did not want to have more choices in her health care might feel very different if she became dissatisfied with her current health care coverage and had no opportunity to change providers.

Making choices is only one aspect of being selfdetermined, and as important as it is, if taken out of that context it can be problematic. Another colleague related a situation she had seen at a group home for people with mental retardation. On a visit she had observed a women with mental retardation standing for hours staring out the front window. When queried about this situation, the group home staff indicated that it was her choice to stand there. On further exploration it was determined that this woman had recently participated in a buddy program where someone from the community came and took her out once a week. This woman was, in essence, waiting for her buddy to take her out. Allowing her to stand there hour after hour was a form of abuse and neglect, not promoting selfdetermination. Had they wanted to support her self-determination, the staff members could have provided her more opportunities to express her preferences and go out into the community, to learn how to make more friends and broaden her social contacts, and to learn how to access transportation to go out more often. Ferleger (1994) commented on the same situation, noting circumstances of:

deprivation or denial of services, or violation of rights, of people with mental retardation based on invocation of "choice" as a guiding principle. For example, people are denied individual habilitation planning or even a case manager because they are said to have chosen to give up such assistance. People are denied a job or meaningful activity because they are said to choose otherwise. People's homes and bedrooms, and daily life choices, are barren and devaluing, all based on what is said to be "choicd." 
Ferleger noted that "some writers, perhaps enamored of the philosophical connections between 'choice' and 'freedom' or perhaps connecting liberation from institutions with some notion of freedom, seem to extol 'choice' as a value supreme to others." Referring to the role of choice in service provision, Ferleger stated "elevation of choice above other elements of normaliza tion inevitably shortchanges the people who we serve."

\section{Self-Determination and People With Significant Disabilities}

Are issues of definition and conceptualizations of selfdetermination important to people with significant disabilities? Although the debate in and of itself may not be, the outcomes of that debate certainly are. One only has to look at the issues surrounding physician-assisted suicide or institutionalization to see the terms self-determination, autonomy, or choice being used to limit access to the community or support physicianassisted suicide. How we define and conceptualize innovations and constructs does matter.

I would like to return to the question posed at the start of this article: "How does self-determination apply to people with significant disabilities?" Given that self-determination refers to control over one's life and destiny, do people with significant disabilities have the right to self-determination? Unequivocally yes. That was the point of Nirje's (1972) chapter, the point of Perske's (1972) call for the dignity of risk, and the central theme sounded by writers like Burton Blatt and Gunnar Dybwad. More importantly, that is the message from people with disabilities and other people who have been left out of the mainstream. It is what is meant by Robert Williams when he describes self-determination as "another word for having the chance to live the American Dream" (Williams, 1989). It is what is meant in federal legislation stating that:

\footnotetext{
"disability is a natural part of the human experience and in no way diminishes the rights of individuals to live independently, enjoy self-determination, make choices, contribute to society, pursue meaningful careers and enjoy full inclusion and integration in the economic, political, social, cultural and educational mainstream of American society"[Rehabilitation Act Amendments of 1992, Sec. 2 (a)(3)(A - F)].
}

Can individuals with significant disabilities be selfdetermined? Again, the answer is unequivocally yes. The education and psychology literature quite clearly show that individuals with significant disabilities can learn to self-regulate and self-manage their own behavior, become less dependent on others, and express preferences and use those preferences to make choices (Wehmeyer et al., 1998). The person-centered future planning procedures implemented in the last decade have shown that people with significant disabilities can be involved in the decision-making process, including making decisions about their own lives (Mount, 1994; Turnbull et al., 1996). The self-advocacy movement has shown that people with significant disability can assertively advocate for their own rights and needs, and the rights and needs of all people with disabilities (Dybwad \& Bersani, 1996).

When the emphasis is not placed on self-determination as independent performance, absolute control, and success, and instead on (a) providing individuals with adequate opportunities to be the causal agent in their lives, make choices, and learn self-determination skills; (b) enabling them to maximally participate in their lives and communities; and (c) ensuring that supports and accommodations are in place, people with significant disabilities can be self-determined.

The challenge before us is to move the discussion from questioning whether self-determination applies to people with significant disabilities to enabling people with significant disabilities to be as self-determined as possible. Just as questions about the employability of people with significant disabilities began to fade as more and more people with significant disabilities entered the workforce as the result of supported employment, so too questions about the applicability of self-determination to people with significant disabilities will begin to fade as more indi-viduals with significant dis abilities take control over their lives. This will require a combination of efforts, often occurring in parallel, that involve: removing systemic and individual barriers that prohibit individuals from assuming greater control (Mithaug, 1996; Nerney \& Shumway, 1996); using behavioral and adaptive technologies to enable individuals to acquire needed skills (Agran, 1997; Baker \& Brightman, 1997; Wehmeyer et al., 1997); applying knowledge about creating individual supports to provide necessary accommodations (Bradley, Ashbaugh, \& Blaney, 1994; Nisbet, 1992); implementing practices that support community inclusion, integration, and meaningful employment and leisure outcomes (Schleien, Meyer, Heyne, \& Brandt, 1995; Taylor, Bogan, \& Lutfiyya, 1995; Wehman \& Moon, 1988); and advocating for federal, state, and local policies that protect individual freedoms and enable persons to pursue self-determination. The good news is that we know how to do all of these things and it is now a matter of will and willingness. Although there is much that must happen to achieve this outcome, from system reform to implementing individual supports and accommodations, these are within our grasp. The bad news is that we have allowed25 years to pass from the time of Nirje's (1972) call and there is no time to wait any longer. Pearl 
Buck, the Pulitzer Prize winning novelist who wrote about her experiences in China in the early part of this century, and is herself the parent of a daughter with a significant disability, once wrote that "None who have always been free can understand the terrible fascinating power of the hope of freedom to those who are not free." (Buck, 1943). I believe this is true for many people with disabilities who have not had the opportunity to experience control over their lives, and that most American's who take such control for granted can never fully comprehend the urgency or the importance of this to people with significant disabilities. It is time to heed Nirje's call.

\section{References}

Abery, B. (1993). A conceptual framework for enhancing selfdetermination. In M. Hayden and B. Abery (Eds.). Challenges for a service system in transition: Ensuring quality community experiences for persons with developmental disabilities (pp. 345-380). Baltimore: Paul H. Brookes.

Abery, B. (1994). Self-determination: It's not just for adults. Impact, 6(4), 2.

Agran, M. (1997). Student-directed learning: Teaching selfdetermination skills. Pacific Grove, CA: Brooks/Cole.

American Heritage Dictionary of the English Language. (1992). New York: Houghton Mifflin Company.

Angyal, A. (1941). Foundations for a science of personality. Cambridge, MA: Harvard University Press.

Baker, B. L, \& Brightman, A. J. (1997). Steps to independence: Teaching everyday skills to children with special needs (3rd Edition). Baltimore: Paul H. Brookes.

Bradley, V. J., Ashbaugh, J. W., \& Blaney, B. C. (1994). Creating individual supports for people with developmental disabilities: A mandate for change at many levels. Baltimore: Paul H. Brookes.

Brown, F., \& Gothelf, C. R. (1996). Self-determination for all individuals. In D. H. Lehr \& F. Brown (Eds.). People with disabilities who challenge the system (pp. 335-353). Baltimore: Paul H. Brookes.

Buck, P. (1943). What America means to me. New York: Columbia University Press.

Carter-Ludi, D., \& Martin, L. (1995). The road to personal freedom: Self-determination. Intervention in School and Clinic, 30, 164-69.

Damon, W. (1983). Social and personality development. New York: W. W. Norton and Co.

Deci, E. L., \& Ryan, R. M. (1985). Intrinsic motivation and self-determination in human behavior. New York: Plenum.

Doll, B., Sands, D. J., Wehmeyer, M. L., \& Palmer, S. (1996). Promoting the development and acquisition of selfdetermined behavior. In D. J. Sands \& M. L. Wehmeyer (Eds.). Self-determination across the life span: Independence and choice for people with disabilities (pp. 63-88). Baltimore: Paul H. Brookes.

Dybwad, G., \& Bersani, H. (1996). New voices: Self-advocacy by people with disabilities. Cambridge, MA: Brookline Books.

Eder, R. (1990). Uncovering young children's psychological selves: Individual and developmental differences. Child Development, 61, 849-863.
Ferleger, D. (1994). The place of "choice." In C. J. Sundram (Ed.). Choice and responsibility: Legal and ethical dilemmas in services for persons with mental disability (pp. 64-97). Albany, NY: New York State Commission on Quality of Care for the Mentally Disabled.

Field, S. (1996). Self-determination instructional strategies for youth with learning disabilities. Journal of Learning Dis abilities, 29, 40-52.

Field, S., \& Hoffman, A. (1994). Development of a model for selfdetermination. Career Development for Exceptional Individuals, 17, 159-169.

Field, S., Martin, J., Miller, R., Ward, M., \& Wehmeyer, M. (1997). A practical guide to teaching self-determination. $\mathrm{Re}-$ ston, VA: Council for Exceptional Children.

Hall, C. S., \& Lindzey, G. (1957). Theories of personality. New York: John Wiley \& Sons.

Jakubowski, P., \& Lange, A. J. (1978). The assertive option: Your rights and responsibilities. Champaign, IL: Research Press Co.

Kennedy, M. (1996). Self-determination and trust: My experiences and thoughts. In D. J. Sands \& M. L. Wehmeyer (Eds.). Selfdetermination across the life span: Independence and choice for people with disabilities (pp. 35-47). Baltimore: Paul H. Brookes.

Levy, R. M., \& Rubenstein, L. S. (1996). The rights of people with mental disabilities. Carbondale, IL: Southern Illinois University Press.

Martin, J. E., \& Marshall, L. H. (1996). ChoiceMaker: Infusing selfdetermination instruction into the IEP and transition process. In D. J. Sands \& M. L. Wehmeyer (Eds.). Self-determination across the life span: Independence and choice for people with disabilities (pp. 215-236). Baltimore: Paul H. Brookes.

Mithaug, D. (1996). Equal opportunity theory. Thousand Oaks, CA: Sage Publications.

Mount, B. (1994). Benefits and limitations of personal futures planning. In V. Bradley, J. W. Ashbaugh, \& B C. Blaney (Eds.). Creating individual supports for people with developmental disabilities: A mandate for change at many levels (pp. 97-108). Baltimore: Paul H. Brookes.

Nerney, T., \& Shumway, D. (1996). Beyond managed care: Selfdetermination for people with disabilities. Durham, NH: University of New Hampshire.

Nirje, B. (1972). The right to self-determination. In W. Wolfensberger (Ed.). Normalization: The principle of normalization (pp. 176-200). Toronto: National Institute on Mental Retardation.

Nisbet, J. (1992). Natural supports in school, at work, and in the community for people with severe disabilities. Baltimore: Paul H. Brookes.

O'Brien, J. (1997). Implementing self-determination initiatives: Some notes on complex change. Lithonia, GA: Responsive Systems Associates.

Perske, R. (1972). The dignity of risk. In W. Wolfensberger (Ed.). Normalization: The principle of normalization in human services (pp. 194-200). Toronto: National Institute on Mental Retardation.

Powers, L. E., Sowers, J., Turner, A, Nesbitt, M., Knowles, E., \& Ellison, R. (1996). Take charge: A model for promoting selfdetermination among adolescents with challenges. In. L. E. Powers, G. H. S. Singer, \& J. Sowers (Eds.). On the road to autonomy: Promoting self-competence in children and youth with disabilities (pp. 291-322). Baltimore: Paul H. Brookes.

Rehabilitation Act Amendments of 1992, P. L. 102-569. (October 29, 1992). Title 29, U.S.C. 701 et seq: U. S. Statutes at Large, $100,4344-4488$ 
Rousso, H. (1997). Seeing the world a new: Science and disabilities. In N. Kreinberg and E. Wahl (Eds.). Thoughts and Needs: Equity in mathematics and science education (pp. 131-134) Washington D.C.: The American Journal for the Advancement of Science.

Sands, D. J., \& Wehmeyer, M. L. (1996). Self-determination across the life span: Independence and choice for people with disabilities. Baltimore: Paul H. Brookes.

Schleien, S. J., Meyer, L. H., Heyne, L. A., \& Brandt, B. B. (1995). Lifelong leisure skills and lifestyles for persons with developmental disabilities. Baltimore: Paul $\mathrm{H}$. Brookes.

Serna, L. A., \& Lau-Smith, J. (1995). Learning with a PURPOSE: Self-determination skills for students who are at risk for school and community failure. Intervention in School and Clinic, 30, 142-146.

Stancliffe, R. J., \& Abery, B. H. (1997). Longitudinal study of deinstitutionalization and the exercise of choice. Mental Retardation, 35, 159-169.

Taylor, S. J., Bogdan, R., \& Lutfiyya, Z. M. (1995). The variety of community experience: Qualitative studies of family and community life. Baltimore: Paul H. Brookes.

Turnbull, A. P., Blue-Banning, M. J., Anderson, E. L., Turnbull, H. R., Seaton, K. A., \& Dinas, P. A. (1996). Enhancing selfdetermination through Group Action Planning. In D. J. Sands \& M. L. Wehmeyer (Eds.). Self-determination across the life span: Independence and choice for people with dis abilities (pp. 237-256). Baltimore, Paul H. Brookes.

Van Reusen, A. K., Bos, C. S., Schumaker, J. B., \& Deshler, D. D. (1994). The self-advocacy strategy for education and transition planning. Lawrence, KS: Edge Enterprises, Inc.

Vaughn, C. E. (1993). The struggle of blind people for selfdetermination: The dependency-rehabilitation conflict; empowerment in the blindness community. Springfield, IL: Charles C. Thomas Publisher.

Ward, M. J. (1996). Coming of age in the age of selfdetermination: A historical and personal perspective. In D. J. Sands \& M. L. Wehmeyer (Eds.). Self-determination across the life span: Independence and choice for people with disabilities (pp. 1-16). Baltimore: Paul H. Brookes.

Ward, M. J., \& Kohler, P. D. (1996). Promoting selfdetermination for individuals with disabilities: Content and process. In L. E. Powers, G. H. S. Singer, \& J. Sowers (Eds.). On the road to autonomy: Promoting self-competence in children and youth with disabilities (pp. 275-290). Baltimore: Paul H. Brookes.

Wehman, P., \& Moon, M. S. (1988). Vocational rehabilitation and supported employment. Baltimore: Paul $\mathrm{H}$. Brookes.
Wehmeyer, M. L. (1996a). Self-determination for youth with significant disabilities: From theory to practice. In. L. E. Powers, G. H. S. Singer, \& J. Sowers (Eds.). On the road to autonomy: Promoting self-competence in children and youth with disabilities (pp. 115-134). Baltimore: Paul $\mathrm{H}$. Brookes.

Wehmeyer, M. L. (1996b). Self-determination as an educational outcome: Why is it important to children, youth and adults with disabilities? In D. J. Sands \& M. L. Wehmeyer (Eds.). Self-determination across the life span: Independence and choice for people with disabilities (pp. 15-34). Baltimore: Paul H. Brookes.

Wehmeyer, M. L. (1997). Self-determination as an educational outcome: A definitional framework and implications for intervention. Journal of Developmental and Physical Disabilities, 9, 175-209.

Wehmeyer, M. L., Agran, M., \& Hughes, C. (1998). Teaching self-determination to youth with disabilities: Basic skills for successful transition. Baltimore: Paul H. Brookes.

Wehmeyer, M. L., Kelchner, K., \& Richards. S. (1996). Essential characteristics of self-determined behaviors of adults with mental retardation and developmental disabilities. American Journal on Mental Retardation, 100, 632-642.

Wehmeyer, M. L., \& Schwartz, M. (1997). Self-determination and positive adult outcomes: A follow-up study of youth with mental retardation or learning disabilities. Exceptional Children, 63, 245-255.

Wehmeyer, M. L., \& Schwartz, M. (1998). The relationship between self-determination and quality of life for adults with mental retardation. Education and Training in Mental Retardation and Developmental Disabilities, 33, 3-12.

Williams, R. R. (1989). Creating a new world of opportunity: Expanding choice and self-determination in lives of Americans with severe disability by 1992 and beyond. In R. Perske (Ed.). Proceedings from the National Conference on SelfDetermination (pp. 16-17). Minneapolis: Institute on Community Integration.

Wolfensberger, W. (1972). Normalization: The principle of normalization. Toronto: National Institute on Mental Retardation.

Wolman, B. B. (1973). Dictionary of behavioral science. New York: Van Nostrand Reinhold Co.

Received: July 31, 1997

Final Acceptance: February 23, 1998

Guest Editor in Charge: Martin Agran 